\title{
Revisiting the Telecommunications Act of 1996
}

Justin S. Brown, University of South Florida

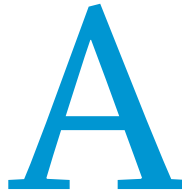

$s$ an APSA congressional fellow, revisiting the Telecommunications Act of 1996 (herein '96 Act) provided several important legislative lessons regarding telecommunication policy. First, it takes parties a considerable amount of time to agree upon major policy formation and laws, whether in a partisan or non-partisan climate. Second, the Internet and digital technology have created an innovative space that is difficult to regulate, especially when it fosters new forms of competition against traditional, incumbent firms and services that often benefit consumer choice and prices. Third, it is still possible for members of two different political parties to sit at the same table with stakeholders and attempt to find common ground and areas to work together to solve existing problems. Fourth, regulation by an agency like the Federal Communications Commission (FCC) is only as effective as the guiding principles set forth in statute. Fifth, it is likely that the deregulatory provisions of the ' 96 Act that fostered the growth of the Internet and digital technology has added a potential new component of innovation to the public interest that will continue to shape telecommunications policy for the considerable future.

Defined broadly, telecommunications involves the various forms of technology that we use to communicate and includes telephony, cable television, satellite, wireless, and the Internet. Telecommunications is important in infrastructure because of its impact on the flow of information and ideas and the perceptions we derive about the rest of the world through our dependency on mass media (Horwitz 1991). Debates over how to best regulate telecommunications are immersed in how one interprets the "public interest" (Aufderheide 1999), which traditionally consists of some combination of the values of competition, universal service, localism, diversity, and a free marketplace of ideas (Napoli 2001).

Despite the growth of digital technology and the Internet over the past 20 years, the ' 96 Act has experienced very little in the way of enacted bills that change the existing statute. Large incumbent firms that participate actively in the telecommunications industry are at a distinct advantage in influencing policy (Chadwick 2013; McChesney 2013). This may in part be attributed to their entrenched stakeholder interests that effectively lobby Congress, participate in administrative rulemakings with the Federal Communications Commission (FCC), and, when needed, obtain favorable court rulings through judicial review.
Chadwick (2013) contends that all media systems are hybrid and have evolved from earlier communication forms. This began with a monopoly structure for wired telephone service until the break-up of AT\&T. Experimentation within telephony provided part of the foundation for the formation of broadcast television. Because of the high up-front, sunk costs of wiring homes, a similar framework was granted to cable television and broadband Internet service providers. To help preserve their interests within this hybrid media structure, Chadwick (2013) suggests large media firms, such as political actors, employ old and new media to their advantage to influence policy.

While the '96 Act has increased overall competition, today there are still many areas of the country that only have one broadband Internet service provider and some rural areas have no service at all (FCC 2016). Large incumbents, like Comcast, benefit greatly from their market position where they are often the only locally franchised provider of cable television service in a market and can bundle video with broadband Internet and phone services. Beyond such horizontal leverage, companies like Comcast are also vertically integrated and own a portion of video content offered to cable television subscribers.

As of now, it seems likely that the Internet will be free of significant regulation for the next several years. The election of President Trump brought about a significant change in general regulatory philosophy that has influenced telecommunications policy, namely a push for greater deregulation. Shortly after taking office, President Trump signed executive orders to establish regulatory reforms across all administrative agencies. Congress, in controlling both the House and Senate, turned to the seldom-used Congressional Review Act to overturn the FCC's broadband privacy order. The FCC, under newly-appointed Chairman Ajit Pai, also plans to rollback network neutrality rules that aim to protect a free and open Internet and treat traffic equally without discrimination, blocking or throttling (Brown 2017).

\section{TELECOMMUNICATIONS ACT OF 1996 \& THE INTERNET}

As the first major rewrite of the Communications Act of 1934, the Telecommunications Act of 1996 helped spur further competition in the wired telephone market, continuing the trend of the previous breakup of AT\&T and the bell operating companies who once controlled local and long distance telephone services and equipment manufacturing. Specifically the '96 Act made it easier for new entities to offer local phone 
service and removed line of business restrictions between local telephone, long distance and cable television. The law also relaxed media ownership provisions and removed cable rate regulation in local markets where effective video competition exists.

Besides spurring more phone and video competition, the '96 Act also established universal service and advanced telecommunications capability measures that provided for greater Internet access and broadband deployment. The rewrite also provided guidance for the FCC to move from analog to digital, high-definition television broadcasting. As a result, new entrants could offer both phone and video services. groups, and think tanks. These meetings, informal and lasting roughly an hour, were designed to get participants to share their perspectives. I posed three general questions: If you could do anything, what would you change about the Telecommunications Act of 1996? What's working? What's not working?

Notes from the meetings were compiled and analyzed to look for common patterns and themes among the participants. While not commonplace in every meeting that took place, collectively six themes emerged: no major rewrite, competition, universal service and broadband deployment, consumer protection, FCC reform, and access to networks and content.

\section{Because today's telecommunications landscape has been digitized across most, if not all, of the various areas that the FCC regulates, the' 96 Act remains a challenge within the context of the Internet.}

Although the '96 Act did very little to clearly define and regulate the Internet, Section 706 promoted its deployment by fostering advanced telecommunications capability, now commonly referred to as broadband. Because today's telecommunications landscape has been digitized across most, if not all, of the various areas that the FCC regulates, the ' 96 Act remains a challenge within the context of the Internet.

The Internet itself maximizes capacity, speed and efficiency, providing the ultimate platform in which content and services may be delivered. Today phone calls, television, video and radio programming that once used discrete and separate delivery mechanisms may now all be digitized and delivered through the Internet.

From a regulatory standpoint, this digital transformation represents a tremendous change. Many of the new competitive entrants using Internet technology-commonly referred to as IP for Internet protocol-fall under less burdensome regulations than their counterparts, which are governed by a specific sets of rules. Moreover, even traditional cable and telephone companies are upgrading their infrastructure and transitioning to IP technology to make delivery and services more efficient (Nuechterlein and Weiser 2013).

Internet and digital technology have made the delivery of what were once mutually exclusive services and technologies possible on a single platform accessible by a variety of different devices. While the '96 Act arguably helped stimulate competition and innovation, Congress may nevertheless wish to provide further guidance to address issues raised by technological and marketplace convergence.

\section{MEETINGS WITH STAKEHOLDERS}

As a congressional fellow, I met with concerned stakeholders about their impressions on whether the ' 96 Act needed to be updated to better reflect current conditions. During the firsthalf of 2016, 33 different stakeholder groups were consulted. The participants included industry trade associations representing incumbent firms regulated by the ' 96 Act, new entrants that fall outside of FCC jurisdiction, public interest
While much of the discussion around these themes is immersed in technical details around technology and specific services, statutes and regulations, the following paragraphs help illustrate general takeaway lessons about the telecommunication policy formation process within Congress.

\section{Both Parties May Still Sit Together at the Same Table}

Even within a highly partisan climate, it is still possible for both parties to work together and aim at building consensus on major pieces of legislation. The hour-long meetings were bipartisan, taking place with the offices of Sen. Roger Wicker (R-MS), sitting chair of the Communications, Technology, Innovation and the Internet subcommittee, and Sen. Brian Schatz (D-HI), the ranking member of that subcommittee. The arrangement of meetings to discuss the ' 96 Act came as a surprise to many of the concerned stakeholders, who often tailor their message to a political actor of one party. Instead, the discussions with stakeholders included reaching out to both political party perspectives. As a result, the collective discourse of the project helped identify specific areas of common ground that may be fruitful for policy deliberation regardless of political party affiliation. Subsequently, both offices worked together to co-sponsor a bipartisan bill, Reaching Underserved Rural Areas to Lead (RURAL) on Telehealth Act (S.3218), which expands access to rural telehealth services supported by the FCC's Health Care Connect Fund.

\section{Major Policy Formation Takes Considerable Time}

Nearly all of the groups involved believed that a comprehensive rewrite was not necessary. There was general agreement that the grand compromises between issues and objectives don't readily exist like they did when the '96 Act was passed. Most conceded that any rewrite is a long process of consensus building that would take considerable time to achieve and that the initial stages of agreement were not readily present.

While stakeholders admitted the status quo isn't perfect, many conveyed a desire for minor fixes germane to 
their specific interests as a preferred route rather than an overhaul. This may be attributed to the fact that there have been considerable lobbying efforts made to achieve policy outcomes during the past 20 years on issues like network neutrality, phone and video competition, and buildout of broadband services. Many also suggested the politics at play within the partisan climate make a rewrite challenging but not impossible.

Only a few of the larger incumbent industry stakeholders argued in a favor of a large rewrite, suggesting it is timely and appropriate to do away with different regulatory structures and allow greater flexibility for market forces to foster competition. These groups were largely in favor of using regulation only as a backstop to prevent anti-competitive practices and protect consumers on an as-needed basis where specific harms are demonstrated.

\section{Let the Internet Continue to Innovate and Foster Competition}

Nearly all stakeholders conveyed support for competition as a regulatory objective. The ' 96 Act's overarching objective was to promote competition in the phone and video markets, and stakeholders wanted to see this trend continue. Many praised the growth of Internet-connected services and applications for stimulating not only competition but also innovation.

Participants suggested it was important for Congress to promote competition and innovation through more technology-neutral policies that provide fair regulatory treatment for similar services. Stakeholders also suggested that Congress needs to address regulatory asymmetry to level the playing field so incumbent firms are not unfairly disadvantaged because of additional rules that new competitors do not face. While one stakeholder suggested at least three competitors are desirable in a single geographic and service/product market, others believed in relying on market forces and using regulation to protect consumers only in instances without any competition. suggested improving universal service funding mechanism to support buildout. Participants widely believed that government needs to make more wireless spectrum available and create streamlined processes to obtain necessary permits and build-out approvals.

\section{FCC Only as Effective as its Clear Statutory Powers}

While most stakeholders recognized the FCC as an "expert agency" responsible for carrying out the provisions set forth in the Communications Act of 1934, ideas varied as to how to make it more effective. Several stakeholders were perfectly content with the FCCs jurisdiction and powers. In contrast, a few suggested near-abolishment of the Commission, calling for it instead to deal mainly with spectrum management and technical issues. Many stakeholders believe the FCC may be more effective in its rulemaking process through enhanced transparency, including adhering to deadlines to gather comments and issue specific rules. Some were also in favor of an effort by the Commission to gather better data, especially in terms of broadband deployment and mapping information. Others believed it was important to have the FCC employ economic analysis as evidence in its decision-making. Finally, some suggested that Congress needed to provide more guidance in general to the FCC to help abate concerns that they are overreaching on emerging issues not readily addressed or anticipated by the ' 96 Act. A prime example lies in the FCC's more than decade-long battle over broadband open access and network neutrality, necessitated because the Internet is not clearly defined by statute.

\section{CONCLUSION}

Serving as a congressional fellow on Capitol Hill provided a rare opportunity to obtain first-hand experience and knowledge about the legislative side of what I've long studiedtelecommunications policy. For years I have examined statutes like the ' 96 Act as interpreted and carried out by the Federal

\section{Nearly all stakeholders conveyed support for competition as a regulatory objective. The '96 Act's overarching objective was to promote competition in the phone and video markets, and stakeholders wanted to see this trend continue.}

Groups in general agreed that broadband services will continue to fuel innovation and competition through promoting Internet-connected services, applications, and devices. Increased broadband deployment and speeds will result in greater benefits to the public, including the growth of wireless applications that are possible with the Internet of Things as well as the next generation of cellular phone services.

To help further broadband deployment and innovation, stakeholders cited a need to provide greater incentives for network investment for both wired and wireless broadband providers. This is especially the case in rural areas where demand and population density make it challenging to offer services. It was within this rural context that some stakeholders
Communications Commission (FCC) and its formal rulemaking process under the Administrative Procedures Act. I have also analyzed the constitutionality and impact of statutes and rulemakings through judicial review. But rarely does an academic work in a Senate office and attend important committee staff meetings, bill markups, oversight hearings, and meetings with concerned stakeholders that aim to influence policy with their unique set of interests and agendas. The lessons of the bipartisan meetings concerning the ' 96 Act left me with a newfound appreciation for just how multilayered telecommunication policy deliberation may be during this time of immense change due to the Internet and digital technology. 


\section{REFERENCES}

Aufderheide, Patricia. 1999. Communications Policy and the Public Interest: The Telecommunications Act of 1996. New York: Guilford Press.

Brown, Justin S. 2017. "Broadband Privacy Within Network Neutrality: The FCC's Application \& Expansion of the CPNI Rules.” University of St. Thomas Journal of Law and Public Policy 11 (1): 45-62.

Chadwick, Andrew. 2013. The Hybrid Media System: Politics and Power. Oxford: Oxford University Press.

Communications Act of 1934, Pub. L. No. 416, 48 Stat. 1064. (1934).

Federal Communications Commission. 2016 Broadband Progress Report, https://apps.fcc.gov/edocs_public/attachmatch/FCC-16-6A1.pdf
Horwitz, Robert Britt. 1991. The Irony of Regulatory Reform: The Deregulation of American Telecommunications. Oxford: Oxford University Press.

McChesney, Robert. 2013. Digital Disconnect: How Capitalism is Turning the Internet Against Democracy. New York: The New Press.

Napoli, Philip. 2001. Foundations of Communication Policy: Principles and Process in the Regulation of Electronic Media. Cresskill, NJ: Hampton Press.

Nuechterlein, Jonathan E., and Philip J Weiser. 2013. Digital Crossroads Telecommunications Law and Policy in the Internet Age. Cambridge, MA: MIT Press.

Telecommunications Act of 1996, Pub. L. No. 104-104, 110 Stat. 56 (codified at 47 U.S.C.151 et. Seq. (Feb 8, 1996) 